\title{
Efficacy of long-term maintenance therapy with mycophenolate mofetil in lupus nephritis
}

\author{
Zahra Rezaieyazdi ${ }^{1 *}$, Tahmine Tavakoli², Mohammad Khajehdaluee ${ }^{3}$ and Shahram Honarmand ${ }^{1}$
}

\begin{abstract}
Background: Mycophenolate mofetil (MMF) has long been used to manage lupus nephritis. Despite research on its long-term efficacy, it is still warranted to conduct further investigation regarding its indications, safety and outcome. This study was intended to evaluate our proposed protocol in maintenance therapy with MMF.

Twenty-four lupus nephritis patients were registered prior to their receiving 3-6 month induction therapy with monthly iv pulses of cyclophosphamide (CYC), followed by 24 month maintenance therapy using MMF and steroid. We defined end points as achievement of complete and partial remission, relapse, refractory to therapy as well as end stage renal disease (ESRD) and death. Friedman and repeated measurement tests were used to assess the effect of treatment on parameters over time.

Complete renal remission was achieved in $79.16 \%$ until the end of the last follow up with an average period of $12.45 \pm 7.37$ months since treatment commenced. Significant statistical differences were seen regarding proteinuria, hematuria, leukocyturia, plasma creatinine, C3, C4 before and after therapy $(\mathrm{P}<0.05)$ : plasma creatinine and proteinurea falling from $0.96 \pm 0.65$ to $0.75 \pm 0.19 \mathrm{mg} / \mathrm{dl}(P<0.14)$ and from $1.64 \pm 1.12$ to $0.27 \pm 0.60 \mathrm{gr} / 24 \mathrm{~h}$ $(\mathrm{P}<0.001)$. By the end of 24 -month, $95.8 \%$ of patients had been in remission. Four episodes of relapse ended in remission followed by retreatment. No life-threatening side effects were observed in $66.6 \%$ of patients with fourteen cases of infection (58.3\%). None of them developed ESRD.

Maintenance therapy with MMF was shown to yield favorable outcome with minimal complications, in treating lupus nephritis (IRCT2012071710313N1).
\end{abstract}

Keywords: Lupus nephritis; Mycophenolate mofetil; Glomerulonephritis

\section{Introduction}

Renal involvement occurs in approximately $40 \%$ of patients with systemic lupus erythematosus. Nephritis is the first manifestation of lupus in 3-6\% of patients and the severity of renal injury determines its prognosis. Generally, survival in lupus patients is roughly $92 \%$ at 10 years after diagnosis. Proliferative renal involvement is among the most severe manifestations of lupus and without proper treatment it can lead to significant morbidity and mortality (Cameron 1999; Mak et al. 2007; Korbet et al. 2007; Contreras et al. 2005; Bernatsky et al. 2006; Hahn et al. 2012).

A logical combination of drugs to achieve specific therapeutic goals is of paramount significance in treating

\footnotetext{
*Correspondence: Rezaieyazdiz@mums.ac.ir

${ }^{1}$ Rheumatic Diseases Research Center, Ghaem Hospital, School of Medicine, Mashhad University of Medical Sciences, Mashhad, Iran

Full list of author information is available at the end of the article
}

lupus nephritis. The core of treatment is based on the application of drugs with maximum efficacy and minimum toxicity in order to control of nephritis to the point of allowing a good quality of life, and non progression of renal disease.

Effective therapy is designed to reduce mortality and prevent progress to end-stage renal disease. Immunosuppressive regimens of glucocorticoids combined with cytotoxic drugs, particularly cyclophosphamide, was effective and standard for the treatment of severe proliferative lupus nephritis (Hahn et al. 2012; Contreras et al. 2004; Ferrantelli et al. 2005; Flanc et al. 2004; Austin et al. 1986; Illei et al. 2001; Gourley et al. 1996; Steinberg and Steinberg 2005; Rezaie-Yazdi et al. 2005; Mok et al. 2001; Ioannidis et al. 2000; Grootscholten et al. 2007). However, cyclophosphamide has both instant and cumulative adverse effects, including marrow suppression, gonadal toxicity, hemorrhagic cystitis, and the increased 
risk of cancer as well as the possibility of no response or relapse in several patients (Houssiau et al. 2002, 2010a). Therefore, other therapeutic agents, such as azathioprine and mycophenolate mofetile with few toxic effects, come prior to other alternatives (Grootscholten et al. 2006; Arends et al. 2012; Sahin et al. 2008; Houssiau et al. 2010b; Dooley et al. 2011).

Nowadays mycophenolate mofetile has been considered an important alternate agent for refractory lupus nephritis with hopeful results and reasonable side effects (Chan et al. 2000, 2005; Lenz et al. 2005; Weng et al. 2010; Zhu et al. 2007; Ong et al. 2005; Karim et al. 2005). Mycophenolic acid, the active metabolite of mycophenolate mofetil, selectively suppresses the proliferation of $\mathrm{T}$ and $\mathrm{B}$ lymphocyte, the formation of antibodies, and the glycosylation of adhesion molecules by inhibiting purine nucleotide synthesis and depleting lymphocytes and monocytes of guanosine triphosphate (Eickenberg et al. 2012). Mycophenolate mofetile as maintenance therapy after short-term intravenous cyclophosphamide have been shown efficient and safe, reducing the long-term exposure to cyclophosphamide (Bernatsky et al. 2006; Flores-Suárez 2006; Borba et al. 2006; Tse et al. 2006). In comparison with cyclophosphamide the adverse effects of MMF have been revealed to be well- tolerated, with gastrointestinal upset being the most common, and no mutagenic effects (Laskari et al. 2010; Elyan and Ballou 2009).

The aim of our study was to evaluate the efficacy and safety of mycophenolate mofetil combined with prednisolone for maintenance treatment of lupus nephritis in a single center cohort of patients with proliferative lupus nephritis.

\section{Patients \& methods}

In this open label clinical trial twenty four consecutive patients with the diagnosis of lupus in accordance with ACR classification criteria (Tan et al. 1982) were enrolled and prospectively followed up during 24 months. All patients had the criteria for nephritis. Renal biopsy was done for 20 patients. Every specimen was observed under light microscopy, the findings of which were subsequently categorized based on the revised World Health Organization (WHO) classification for lupus nephritis (Weening et al. 2004).

Inclusion criteria were defined by one of the followings:

- Evidence of active proliferative glomerulonephritis in the renal biopsy (WHO class IV, III)

- In case of absent renal biopsy or the presence of WHO class $\mathrm{V}$ in biopsy, with the presence of the following clinical or paraclinical findings:

a) Proteinaria $>1 \mathrm{gr} / 24 \mathrm{~h}$ b) Progressive renal failure with $30 \%$ decrease in creatinine clearance over one-year period and creatinine $>1.9 \mathrm{mg} / \mathrm{dL}$

c) The presence of more than 5 red cells in HPF of urine sediment in two separate specimens taken in a year, presence of WBC, granular or hyaline casts without active infection (was examined under conventional light microscope)

\section{Exclusion criteria include:}

WHO class I or II lupus nephritis, end stage renal disease when replacement renal therapy will be indicated, leukopenia (neutrophils $<1500 / \mathrm{mm} 3$ ) due to bone marrow suppression, recurrent episodes of bacterial infection, history of cytotoxic drug treatment for more than two weeks or pulse therapy with corticosteroids during a six-week period before study entry.

\section{Study protocol and immunosuppressive treatment}

For classes III and IV of lupus nephritis, the treatment considered as four phases:

1) Induction: intravenous cyclophosphamide, given as boluses once a month for 3-6 consecutive months (to the maximum dose of $1 \mathrm{~g} / \mathrm{m} 2$ ) in addition to corticosteroid. All patients received ondansetron to prevent nausea and vomiting with every CYC pulse. High dose glucocorticoid was initiated with ivtravenous pulse methylprednisolon (500-1000 mg given over 30 minutes daily for three days) then changed to oral prednisolon (40-60 mg) for one month, tapered to intermediate dose during maintenance phase of therapy.

2) Maintenance: mycophenolate mofetil (cellcept ${ }^{\oplus}$, manufactured by Zahravi Pharm.Co, Under License of F. Hoffmann-La Roche Ltd, Basel, Switzerland) to the maximum dose of $2 \mathrm{gr} /$ day combined with corticosteroid.

3) Tapering: mycophenolate mofetil dosage remains unchanged for the first year followed by dose reduction in the second year, in the absence of relapse or partial remission fulfillment.

When partial remission was achieved, we started to taper prednisolon by an average of $10 \%$ monthly in order to reach an optimum dose of 5-10 mg/day.

4) Discontinuation: if our study goals had been achieved, the mycophenolate mofetil would have been discontinued with the further tapering of prednisolone to the lowest possible daily dose and patients' follow-up for evidence of relapse. 
Those with class $\mathrm{V}$ lupus nephritis were given mycophenolate mofetil combined with corticosteroid since the diagnosis was made.

Patients were followed up every month during induction therapy and every other month during the first year and every three months thereafter. During each visit, the patients were evaluated including a complete physical examination as well as all laboratory and serologic tests (blood count, urine analysis, creatinine, GFR, measurement of proteinuria in $24 \mathrm{~h}$ urine collection, C3, C4, Anti-DNA, ANA, ESR). At each visit, side effects were investigated via enquiry and thorough physical examination. Each patient had a complete clinical evaluation for any other organ involvement besides nephritis as well as episodes of relapse.

Informed consent was obtained from all patients. The design of the work has been approved by the ethical committee of Mashhad University of Medical sciences.

\section{End points were defined as}

Criteria for complete remission:

a) Complete improvement of renal and extra-renal symptoms:

Rise of creatinine less than $0.3 \mathrm{mg} / \mathrm{dL}$, less than $300 \mathrm{mg}$ proteinuria per day (only trace proteinuria) or less than $50 \%$ of initial proteinuria when $\mathrm{Cr}>1.7 \mathrm{mg} / \mathrm{dl}$, absence of RBC cast, complete regression of all systemic symptoms

b) Return to within normal limits of ESR, C3, C4, Hb and fall of autoantibody titers

c) Absence of relapses and infectious complications

Criteria for partial remission:

a) No progression of renal disease (normal or stable renal function)

b) Decrease of at least 50\% in dysmorphic RBC, cellular casts and proteinuria in the absence of doubling of serum creatinine or less than 1 gr proteinuria per day

c) Return to within normal limits of markers of inflammation such as ESR

d) Regression of systemic symptoms

e) Return of patient to functional class 2 in the presence of an acceptable rate of complications

Relapse:

a) More than 50\% increase in (after reaching the lowest level during therapy) serum creatinine, dysmorphic RBC, cellular cast

b) Doubling of proteinuria if there was nephritic proteinuria or at least $2 \mathrm{gr} /$ day if based proteinuria $<3.5$ gr/day

c) At least two systemic symptoms reappeared
Refractory to therapy:

a) No renal response in spite of 6 month treatment with mycophenolate mofetil

End stage renal disease:

a) Plasma creatinine rose and got stabilized above $5 \mathrm{mg} / \mathrm{dl}$ for 3 months

\section{Statistical analysis}

Analyses of all data were conducted in SPSS version 11.5. The significance of the process of changes of variables with abnormal distribution was assessed by Friedman test whereas those with normal distribution were tested by repeated measurement.

Wilcoxon signed ranks test was used for comparing quantitative variables with abnormal distribution while Paired t-test was applied to variables with normal distribution. All mean values were shown $\pm 1 \mathrm{SD}$ and $\mathrm{P}$ values $<0.05$ were considered statistically significant.

\section{Results}

\section{Patients' characteristics}

We enrolled 20 females and 4 males with active lupus nephritis with majority documented with diffuse proliferative glomerulonephritis. Two tissue samples (10\%) were compatible with WHO class III, 13 samples were WHO class IV (65\%) and 5 samples were WHO class V (25\%). Adverse predictive factors such as proteinuria, low GFR, hypertention, were detected in $95.8 \%, 33.3 \%$ and $41.6 \%$ of patients respectively. At the beginning of renal disease 21 patients had hematuria and 18 patients had leukocyturia. The average range of proteinuria before treatment was $1.57 \pm 1 \mathrm{gr} /$ day. Three patients (13\%) had nephrotic syndrome (proteinuria $>3 \mathrm{gr} /$ day). Decrease in C3 and C4 levels were seen in $33.30 \%$ at the beginning of therapy. Anti DNA was positive in $50 \%$ of patients. Renal insufficiency means creatinine $>1.9 \mathrm{mg} / \mathrm{dL}$ was seen in one patient at the beginning of therapy.

Extra renal manifestations at baseline are as follows: skin rash $13(54.2 \%)$, arthritis $15(62.5 \%)$, oral ulcer 16 (66.7\%), vasculitis $3(12.5 \%)$, nervous system involvement $3(13 \%)$, cardiac involvement $1(4.2 \%)$ and pneumonitis 1 (4.2\%). Baseline characteristics of 24 patients with lupus nephritis are shown in Table 1.

Results of the statistical comparisons among selected variables at baseline and at the latest follow up showed a significant improvement of all parameters including proteinuria, C3 and C4 (Table 2). Then we evaluated laboratory data variables changes during the course of treatment.

Significant alterations could be observed in proteinuria which resolved in 20 out of 24 (83.3\%) patients (Figure 1), 
Table 1 Characteristics of twenty four patients with lupus nephritis

\begin{tabular}{lcc}
\hline Characteristics & Mean & Range \\
\hline Age (year) & $20.7 \pm 8.1$ & $10-40$ \\
Duration between onset of lupus & $15.17 \pm 22.79$ & $0-84$ \\
and renal involvement (month) & & \\
Serum Creatinine (mg/dl) & $0.95 \pm 0.63$ & $0.10-3.5$ \\
GFR(ml/min/1.73 $\left.\mathrm{m}^{2}\right)$ & $83.19 \pm 32.99$ & $20.40-162.91$ \\
Urinary protein (g/24 h) & $1.57 \pm 1.11$ & $0.10-4.3$ \\
Serum C3 (mg/dl) & $63.12 \pm 28.46$ & $14-120$ \\
Serum C4 (mg/dl) & $17.19 \pm 8.38$ & $6-35$ \\
Platlete (number/mm $\left.{ }^{3}\right)$ & $255 \pm 93 \times 10^{3}$ & $63-511 \times 10^{3}$ \\
Serum Hb (mg/dl) & $12.01 \pm 1.72$ & $8.8-15.9$ \\
ESR/h & $32.79 \pm 28.08$ & $4-130$ \\
Systolic BP (mmHg) & $129.58 \pm 22.69$ & $80-180$ \\
Diastolic BP (mmHg) & $86.04 \pm 14.25$ & $60-120$ \\
Urine WBC (n/hpf) & $19.25 \pm 27.38$ & $0-100$ \\
Urine RBC (n/hpf) & $21.87 \pm 31.15$ & $0-100$ \\
\hline
\end{tabular}

and hematuria $(\mathrm{P}<0.001)$, whereas parameters such as platlete count, $\mathrm{Hb}$ and ESR seemed immune to drastic changes $(\mathrm{P}=0.31, \mathrm{P}=0.88, \mathrm{P}=0.24)$. The creatinine level changes during the course of therapy has been shown in Figure $2(P=0.68)$. As to renal involvement implications systolic and diastolic blood pressure varied in their pattern of, with the latter falling substantially $(P=0.02)$ while the former remained almost unchanged $(\mathrm{P}=0.09)$.

As can be seen in the Figure 3, initial response to therapy began since the first month following drug administration in accordance with our protocol. Sixteen cases were shown to match partial remission criteria at the end of the third month, and one patient achieved full remission; which could first be seen at the end of the third month, gaining momentum at a sharp pace to peak at around month 21 .

Table 2 Statistical comparisons of selected variables prior to and following treatment

\begin{tabular}{lccc}
\hline Parameters & Before $($ mean \pm SD) & After $($ mean \pm SD) & P value \\
\hline Proteinuria(gr/24 h) & $1.57 \pm 1.11$ & $0.27 \pm 0.60$ & $<0.001$ \\
Hematuria(n/hpf) & $21.87 \pm 31.15$ & $2.28 \pm 3.42$ & $<0.001$ \\
Leukocyturia(n/hpf) & $19.25 \pm 27.38$ & $2.85 \pm 5.59$ & 0.001 \\
C3(mg/dl) & $63.12 \pm 28.46$ & $97.79 \pm 20.73$ & $<0.001$ \\
C4(mg/dl) & $17.19 \pm 8.38$ & $23.41 \pm 8.47$ & 0.006 \\
Creatinine $(\mathrm{mg} / \mathrm{dl})$ & $0.96 \pm 0.95$ & $0.75 \pm 0.19$ & 0.144 \\
GFR(ml/min/1.73 $\left.\mathrm{m}^{2}\right)$ & $83.19 \pm 32.99$ & $98.96 \pm 26.73$ & 0.060 \\
\hline
\end{tabular}

\section{Outcome measures}

Partial renal remission

With a mean renal remission time of $3.67 \pm 2.58$ months from baseline, five out of 24 patients (20.83\%) reached partial renal remission.

\section{Complete renal remission}

Complete renal remission was achieved in 19 out of 24 patients $(79.16 \%)$ at the end of the last follow up. Average period of complete remission was $12.45 \pm 7.37$ month since the beginning of treatment.

At the end of follow-up, 23 out of 24 patients (95.8\%) of the patients had reached remission.

\section{Renal relapse}

Relapses occurred during the maintenance phase of therapy in 4 out of 24 patients in remission (16.6\%).

Relapses happened at $15^{\text {th }}, 18^{\text {th }}$ and $21^{\text {st }}$ months of therapy and all patients except one responded when retreated with cyclophosphamide pulse followed by mycophenolate mofetil.

\section{Chronic renal failure-death}

There was no refractory-to-therapy case. None of our patients developed chronic renal insufficiency or died.

\section{Extra renal manifestation and pregnancy}

The majority of the initial extra renal manifestations resolved during the maintenance phase of therapy. None of our patients developed sustained amenorrhea. During this treatment course, we had four patients who had been pregnant at $8^{\text {th }}, 10^{\text {th }}, 15^{\text {th }}$ and $21^{\text {th }}$ months since treatment commenced, when they were in partial remission, ending in unproblematic delievery. Azathioprine replased mycophenolate mofetil throught pregnancy period, with one relapse episode following delivery.

\section{Side effects}

Side effects were observed in sixteen out of the 24 patients (66.6\%) with fourteen cases of infection (58.3\%).

No hemorrhagic cystitis was observed while transient gastrointestinal complications affected two patients during maintenance therapy (12\%) (diarrhea, gastrointestinal discomfort and nausea).

\section{Discussion}

Mainstream therapy is primarily intended to improve renal function as well as to prevent progressive disease. Mycophenolate mofetil was approved for clinical use in lupus nephritis over the past years. Several studies have been conducted on mycophenolate mofetil for maintenance therapy of lupus nephritis (Hahn et al. 2012; Sahin et al. 2008; Houssiau et al. 2010b; Dooley et al. 2011; Chan et al. 2000, 2005; Lenz et al. 2005; Weng et al. 


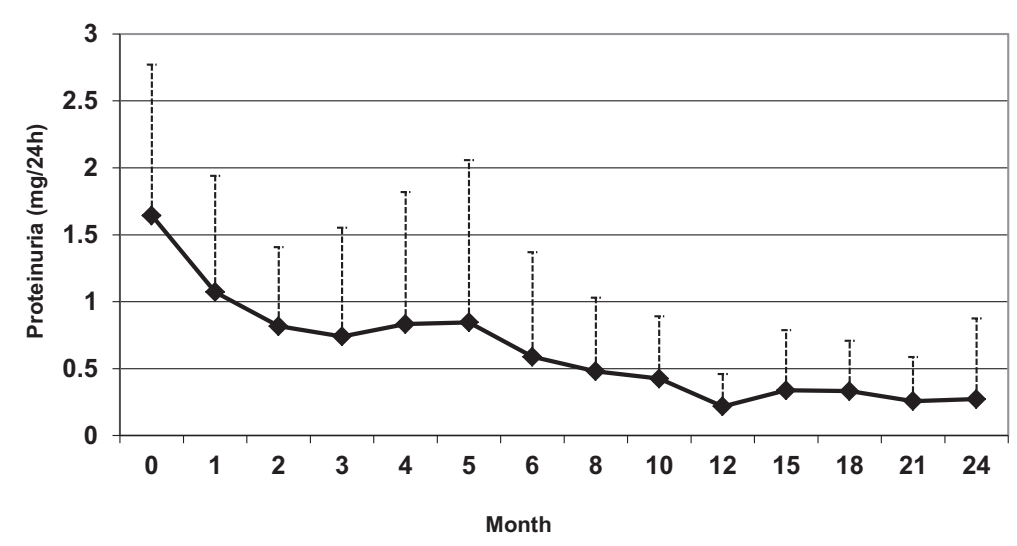

Figure 1 Proteinuria and its changes during the course of follow up.

2010; Karim et al. 2005; Flores-Suárez 2006; Borba et al. 2006; Tse et al. 2006; Laskari et al. 2010; Elyan and Ballou 2009; Ginzler et al. 2005; Mak et al. 2009).

On the basis of anecdotal reports of success with mycophenolate mofetil in patients with lupus nephritis with a considerable likelihood for poor outcomes (Chan et al. 2000, 2005; Lenz et al. 2005; Ginzler et al. 2005), in the present study we intended to examine the safety and efficacy of MMF as maintenance therapy for proliferative lupus nephritis following a short-term induction therapy with iv CYC. Favorable response with acceptable side effects were observed in most patients.

Of the 24 patients treated based on our therapeutic protocol, partial as well as full remission could be achieved in a significant percentage, $95.8 \%$ of the patients, while relapse rates were as low as $16.6 \%$. Our study was free of severe complications such as renal failure and mortality. We had the acceptable rate of relapse, $16.6 \%$ after the $15^{\text {th }}$ month, during the course of therapy, all of whom treated with short-course cyclophosphamide pulse therapy and mycophenolate mofetil to achieved remission. All cases of relapse were seen one year following the last pulse of cyclophosphamide in the third phase of therapy when
MMF dose was reduced. This may indicate that our patients might have needed a longer period of treatment in the second phase. The dose of prednisolon has also been reduced in the third phase. Relapses could have been delayed had steroid been tapered at a slower pace.

One interesting point regarded successful pregnancies among our patients thought our course of therapy. These cases were in $10^{\text {th }}, 15^{\text {th }}$ and $21^{\text {st }}$ month of treatment when the patients were in partial remission. Another case was in her $8^{\text {th }}$ month and in complete remission but lupus nephritis relapsed following delivery.

The response rate to MMF therapy in this study was significant and compatible with other reports. Similar to Chan et al. study on 21 and 33 patients who showed $81 \%$ and $72.7 \%$ complete remission with MMF therapy (Chan et al. 2000, 2005).

In the study of Elyan and Ballou (Elyan and Ballou 2009) on 25 patients with lupus nephritis treated with MMF, $57 \%$ and $17 \%$ of patients achieved complete remission and partial remission in order. On average it took our cases 3.6 and 12.4 months to achieve partial and full remission respectively whereas Elyan and Ballou reported an average of 8.5 month. Results of the statistical

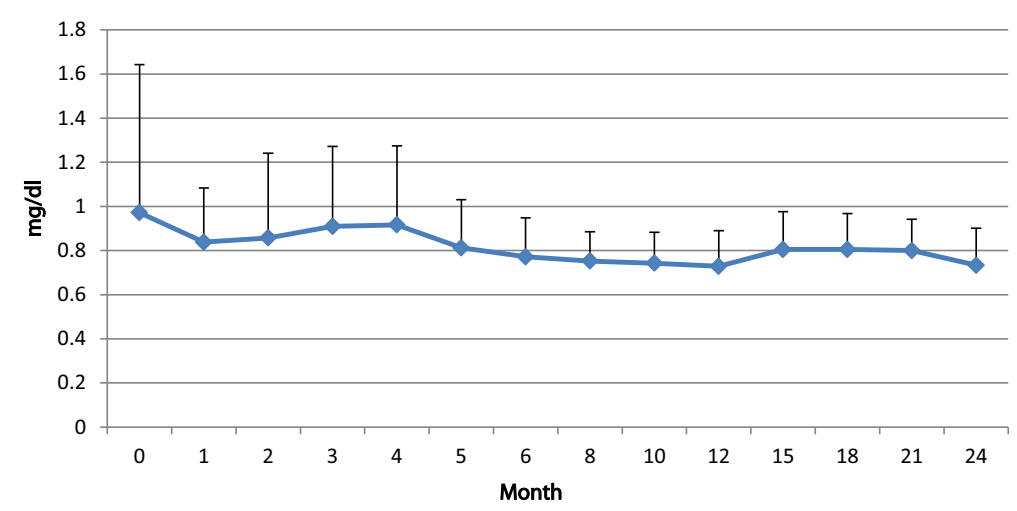

Figure 2 Creatinin and its changes during the course of follow up. 


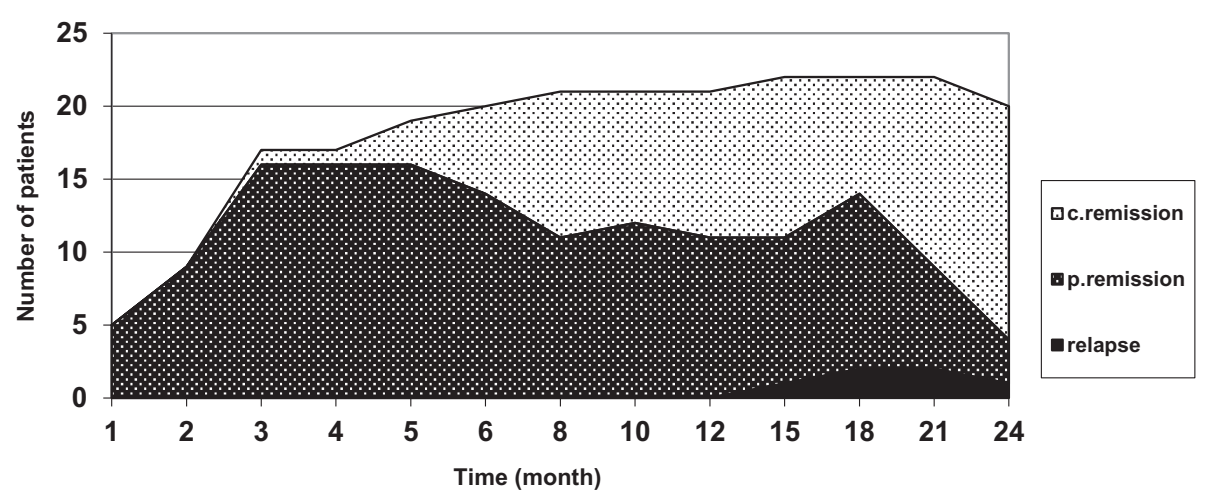

Figure 3 The process of changes of patients responses to treatment during the course of follow up.

comparisons among hematuria, leukocyturia, proteinuria, C3 and C4 showed significant differences before and after treatment, with GFR and creatinine changing slightly which was similar to Elyan and Ballou study (Elyan and Ballou 2009).

As our only three cases of relapse occurred throughout the tapering phase, we may safely conclude that early reduction in steroid and mycophenolate mofetil dosage can account for them.

However, one case of relapse following delivery can also be explained owing to replacing MMF with azathioprine.

Alteration trends pertaining to laboratory finding variables during the course of treatment were also shown almost parallel with other reports findings (Laskari et al. 2010; Elyan and Ballou 2009). Ginzler EM et al. published multicenter, randomized clinical trial and showed that MMF is an appropriate alternative to CYC for the treatment of renal diseases in patients with biopsy-proven lupus nephritis (Ginzler et al. 2005). Our study was in agreement with their observations.

In Laskari et al. (2010) study from Greece, thirty-three consecutive patients with proliferative lupus nephritis received oral MMF $2 \mathrm{~g}$ /day as maintenance therapy for a median time of 29 months. They showed a significant improvement of all renal parameters at the end of the induction treatment as well as at the latest follow-up compared to the baseline. Renal remission achievement rate to the end of the follow-up was $73 \%$ whereas it was $54 \%$ for complete remission cases. They reported 4 (12\%) patients who relapsed within 19-39 months after initial response. At the end of their follow-up, 51\% of patients had reached remission. Their results were in agreement with ours except for the fact that we had fewer side effects in comparison with the Laskari et al. findings (Laskari et al. 2010).

In our clinical trial, there were only two gastrointestinal complications due to MMF which is generally reversible and in comparison with cyclophosphamide side effects, seems insubstantial. The majority of women preserved ovarian function, with four pregnancies. Bone marrow suppression was not a complication of MMF in our study. In contrast to the study by Contreras et al., in which 1 episode of chronic renal failure and 1 death due to severe infection happened, such outcomes were not observed in our cases (Contreras et al. 2004). Some advantages of this study with regard to well defined criteria for examined parameters include lower dose of MMF and long-term follow-up with regular intervals.

The present study suggests that small dose MMF combined with the shortest duration of CYC therapy may be safer than long-term use of CYC without compromising efficacy. This investigation had not been intended for evaluating the effectiveness of MMF as induction therapy in proliferative lupus nephritis. However, there have been reports highlighting the role of MMF in inducing remission (Zhu et al. 2007; Mak et al. 2009; Lee et al. 2010; Walsh et al. 2007; Hui et al. 2013). According to previous data a better outcome with MMF has been demonstrated for non-Caucasian patients (Lee et al. 2010), with considering the fact that our patients were Caucasian, the present study results may put emphasis on the benefit and safety of long term use of MMF in Caucasian race. Future large cohort study of lupus nephritis patients with well defined and strict criteria for all examined parameters such as criteria for full remission, partial remission, relapse, flare as well as the opportunity to have long period of regular follow up would establish our observations.

We were also restricted in terms of the following: As it was an open label clinical trial, there was no control group then the possibility of randomization and masking was not considerable. As continuous follow up and repeated observations of variables in different time interval was performed, so there was possibility of measurements biases due to mean reversion phenomenon. Moreover, the limited numbers of patients made it impossible to generalize our findings in Caucasian race. Other factors 
that limited our study were the lack of any plan for rebiopsy after course of treatment.

On the other hand, our study contain valuable data on the main concern of maintenance treatment in lupus nephritis given the long period of follow up, the clear design and regular follow up of all patients. Randomized controlled trials containing a larger group could corroborate our findings.

In sum, we concluded that mycophenolate mofetil appear to be efficacious and very safe as maintenance treatment for proliferative lupus nephritis following an intensive induction therapy with a short-course of monthly iv, endoxan pulse. That improved renal remission and reduce relapse rates as well as reduction in cyclophosphamide toxicity.

\section{Competing interests}

The authors declare that they have no competing interests.

\section{Authors' contributions}

ZR: Conception and design of the clinical trial, referred the patients, analyzing and interpretation the data, reading and improving the manuscript, revise the final manuscript in response to reviewers' comments. She takes responsibility for the accuracy of study design and data analysis of this clinical trial. She has also been in charge of treatments and follow up plan. TT: Prepare of the research proposal, gathering data from the patients, writing main draft of the manuscript and revise the final version. MK: Helping in designing the clinical trial, doing statistical analysis, revise the statistical aspects of the final version of the maneuscript in accordance with reviewers' comments. SH: Acquisition of the data and helping in drafting the manuscript. All authors read and approved the final manuscript.

\section{Author details}

${ }^{1}$ Rheumatic Diseases Research Center, Ghaem Hospital, School of Medicine, Mashhad University of Medical Sciences, Mashhad, Iran. ${ }^{2}$ Internal Medicine, Brigand University of Medical Sciences, Brigand, Iran. ${ }^{3}$ Community Medicine, Mashhad University of Medical Sciences, Mashhad, Iran.

Received: 2 February 2014 Accepted: 29 September 2014

Published: 28 October 2014

\section{References}

Arends S, Grootscholten C, Derksen RHWM, Berger SP, de Sévaux RGL, Voskuyl AE, Bijl M, Berden JH (2012) Long-term follow-up of a randomised controlled trial of azathioprine/methylprednisolone versus cyclophosphamide in patients with proliferative lupus nephritis. Ann Rheum Dis 71(6):966-973

Austin H, 3rd, Klippel JH, Balow JE, Le Riche N, Steinberg AD, Plotz PH, Decker JL (1986) Therapy of lupus nephritis. Controlled trial of prednisone and cytotoxic drugs. N Engl J Med 314(10):614

Bernatsky S, Boivin JF, Joseph L, Manzi S, Ginzler E, Gladman DD, Urowitz M, Fortin PR, Petri M, Barr S, Gordon C, Bae SC, Isenberg D, Zoma A, Aranow C, Dooley MA, Nived O, Sturfelt G, Steinsson K, Alarcón G, Senécal JL, Zummer M, Hanly J, Ensworth S, Pope J, Edworthy S, Rahman A, Sibley J, El-Gabalawy H, McCarthy T, et al: (2006) Mortality in systemic lupus erythematosus. Arthritis Rheum 54(8):2550-2557

Borba EF, Guedes LK, Christmann RB, Figueiredo CP, Gonçalves CR, Bonfá E (2006) Mycophenolate mofetil is effective in reducing lupus glomerulonephritis proteinuria. Rheumatol Int 26(12):1078-1083

Cameron JS (1999) Lupus nephritis. J Am Soc Nephrol 10(2):413-424

Chan TM, Li FK, Tang CSO, Wong RWS, Fang GX, Ji YL, Lau CS, Wong AK, Tong MK, Chan KW, Lai KN (2000) Efficacy of mycophenolate mofetil in patients with diffuse proliferative lupus nephritis. New Engl J Med 343(16):1156-1162

Chan TM, Tse KC, Tang CSO, Mok MY, Li FK (2005) Long-term study of mycophenolate mofetil as continuous induction and maintenance treatment for diffuse proliferative lupus nephritis. J Am Soc Nephrol 16(4):1076-1084
Contreras G, Pardo V, Leclercq B, Lenz O, Tozman E, O'Nan P, Roth D (2004) Sequential therapies for proliferative lupus nephritis. New Engl J Med 350(10):971-980

Contreras G, Pardo V, Cely C, Borja E, Hurtado A, De La Cuesta C, Iqbal K, Lenz O, Asif A, Nahar N, Leclerq B, Leon C, Schulman I, Ramirez-Seijas F, Paredes A, Cepero A, Khan T, Pachon F, Tozman E, Barreto G, Hoffman D, Almeida Suarez M, Busse JC, Esquenazi M, Esquenazi A, Garcia Mayol L, Garcia Estrada H (2005) Factors associated with poor outcomes in patients with lupus nephritis. Lupus 14(11):890-895

Dooley MA, Jayne D, Ginzler EM, Isenberg D, Olsen NJ, Wofsy D, Eitner F, Appel GB, Contreras G, Lisk L, Solomons N, ALMS Group (2011) Mycophenolate versus azathioprine as maintenance therapy for lupus nephritis. New Engl J Med 365(20):1886-1895

Eickenberg S, Mickholz E, Jung E, Nofer JR, Pavenstadt HJ, Jacobi AM (2012) Mycophenolic acid counteracts B cell proliferation and plasmablast formation in patients with systemic lupus erythematosus. Arthritis Res Ther 14(3):R110

Elyan M, Ballou S (2009) The effectiveness and safety of mycophenolate mofetil in lupus nephritis. Clin Rheumatol 28(7):835-840

Ferrantelli A, Bono L, Tortorici C, Termini R, Giammarresi C, Rotolo U (2005) Treatment of lupus nephritis. G Ital Nefrol 22:S27

Flanc RS, Roberts MA, Strippoli G, Chadban SJ, Kerr PG, Atkins RC (2004) Treatment of diffuse proliferative lupus nephritis: a meta-analysis of randomized controlled trials. Am J Kidney Dis 43(2):197

Flores-Suárez LF (2006) Remission of severe relapsing or persistent lupus nephritis using mycophenolate mofetil. Arch Med Res 37(1):68-73

Ginzler EM, Dooley MA, Aranow C, Kim MY, Buyon J, Merrill JT, Petri M, Gilkeson GS, Wallace DJ, Weisman MH, Appel GB (2005) Mycophenolate mofetil or intravenous cyclophosphamide for lupus nephritis. New Engl J Med 353(21):2219-2228

Gourley MF, Austin H, 3rd, Scott D, Yarboro CH, Vaughan EM, Muir J, Boumpas DT, Klippel JH, Balow JE, Steinberg AD (1996) Methylprednisolone and cyclophosphamide, alone or in combination, in patients with lupus nephritis. A randomized, controlled trial. Ann Intern Med 125(7):549

Grootscholten C, Ligtenberg G, Hagen E, Van den Wall BA, de Glas-Vos J, Bijl M, Assmann KJ, Bruijn JA, Weening JJ, van Houwelingen HC, Derksen RH, Berden $J H$ (2006) Azathioprine/methylprednisolone versus cyclophosphamide in proliferative lupus nephritis. A randomized controlled trial. Kidney Int 70(4):732-742

Grootscholten C, Bajema IM, Florquin S, Steenbergen EJ, Peutz-Kootstra CJ, Goldschmeding R, Bijl M, Hagen EC, Van Houwelingen HC, Derksen RH, Berden JH (2007) Treatment with cyclophosphamide delays the progression of chronic lesions more effectively than does treatment with azathioprine plus methylprednisolone in patients with proliferative lupus nephritis. Arthritis Rheum 56(3):924-937

Hahn BH, McMahon MA, Wilkinson A, Wallace WD, Daikh DI, Fitzgerald JD, Karpouzas GA, Merrill JT, Wallace DJ, Yazdany J, Ramsey-Goldman R, Singh K, Khalighi M, Choi SI, Gogia M, Kafaja S, Kamgar M, Lau C, Martin WJ, Parikh S, Peng J, Rastogi A, Chen W, Grossman JM (2012) American College of Rheumatology guidelines for screening, treatment, and management of lupus nephritis. Arthritis Care Res 64(6):797-808

Houssiau FA, Vasconcelos C, D'Cruz D, Sebastiani GD, Garrido ER, Danieli MG, Abramovicz D, Blockmans D, Mathieu A, Direskeneli H, Galeazzi M, Gül A, Levy Y, Petera P, Popovic R, Petrovic R, Sinico RA, Cattaneo R, Font J, Depresseux G, Cosyns JP, Cervera R (2002) Immunosuppressive therapy in lupus nephritis: The Euro-Lupus Nephritis Trial, a randomized trial of low-dose versus high-dose intravenous cyclophosphamide. Arthritis Rheum 46(8):2121-2131

Houssiau FA, Vasconcelos C, D'Cruz D, Sebastiani GD, de Ramon GE, Danieli MG, Abramovicz D, Blockmans D, Cauli A, Direskeneli H, Galeazzi M, Gül A, Levy Y, Petera P, Popovic R, Petrovic R, Sinico RA, Cattaneo R, Font J, Depresseux G, Cosyns JP, Cervera R (2010a) The 10-year follow-up data of the EuroLupus Nephritis Trial comparing low-dose and high-dose intravenous cyclophosphamide. Ann Rheum Dis 69(01):61-64

Houssiau FA, D'Cruz D, Sangle S, Remy P, Vasconcelos C, Petrovic R, Fiehn C, de Ramon Garrido E, Gilboe IM, Tektonidou M, Blockmans D, Ravelingien I, le Guern V, Depresseux G, Guillevin L, Cervera R (2010b) Azathioprine versus mycophenolate mofetil for long-term immunosuppression in lupus nephritis: results from the MAINTAIN Nephritis Trial. Ann Rheum Dis 69(12):2083-2089

Hui M, Garner R, Rees F, Bavakunji R, Daniel P, Varughese S, Srikanth A, Andres M, Pearce F, Leung J, Lim K, Regan M, Lanyon P (2013) Lupus nephritis: a 15-year multi-centre experience in the UK. Lupus 22(3):328-332 
Illei GG, Austin HA, Crane M, Collins L, Gourley MF, Yarboro CH, Vaughan EM, Kuroiwa T, Danning CL, Steinberg AD, Klippel JH, Balow JE, Boumpas DT (2001) Combination therapy with pulse cyclophosphamide plus pulse methylprednisolone improves long-term renal outcome without adding toxicity in patients with lupus nephritis. Ann Intern Med 135(4):248

loannidis JPA, Boki KA, Katsorida ME, Drosos AA, Skopouli FN, Boletis JN, Moutsopoulos HM (2000) Remission, relapse, and re-remission of proliferative lupus nephritis treated with cyclophosphamide. Kidney Int 57(1):258-264

Karim M, Pisoni C, Ferro L, Tungekar M, Abbs I, D'Cruz D, Khamashta MA, Hughes GR (2005) Reduction of proteinuria with mycophenolate mofetil in predominantly membranous lupus nephropathy. Rheumatology 44(10):1317-1321

Korbet SM, Schwartz MM, Evans J, Lewis EJ (2007) Severe lupus nephritis: racial differences in presentation and outcome. J Am Soc Nephrol 18(1):244-254

Laskari K, Mavragani CP, Tzioufas AG, Moutsopoulos HM (2010) Mycophenolate mofetil as maintenance therapy for proliferative lupus nephritis: a long-term observational prospective study. Arthritis Res Ther 12(6):R208

Lee Y, Woo J, Choi S, Ji J, Song G (2010) Induction and maintenance therapy for lupus nephritis: a systematic review and meta-analysis. Lupus 19(6):703-710

Lenz O, Fornoni A, Contreras G (2005) Defining the role of mycophenolate mofetil in the treatment of proliferative lupus nephritis. Drugs 65(17):2429-2436

Mak A, Mok C, Chu W, To C, Wong S, Au T (2007) Renal damage in systemic lupus erythematosus: a comparative analysis of different age groups. Lupus 16(1):28-34

Mak A, Cheak AAC, Tan JYS, Su HC, Ho RCM, Lau CS (2009) Mycophenolate mofetil is as efficacious as, but safer than, cyclophosphamide in the treatment of proliferative lupus nephritis: a meta-analysis and metaregression. Rheumatology 48(8):944-952

Mok CC, Ho CT, Siu YP, Chan KW, Kwan TH, Lau CS, Wong RW, Au TC (2001) Treatment of diffuse proliferative lupus glomerulonephritis: a comparison of two cyclophosphamide-containing regimens. Am J Kidney Dis 38(2):256

Ong LM, Hooi LS, Lim TO, Goh BL, Ahmad G, Ghazalli R, Teo SM, Wong HS, Tan SY, Shaariah W, Tan CC, Morad Z (2005) Randomized controlled trial of pulse intravenous cyclophosphamide versus mycophenolate mofetil in the induction therapy of proliferative lupus nephritis. Nephrology 10(5):504-510

Rezaie-Yazdi Z, Forghanizadeh J, Rezaie J, Salehian P, Mansouri TH (2005) Combination therapy with pulse cyclophosphamide plus corticosteroids improves renal outcome in patients with lupus nephritis

Sahin GM, Sahin S, Kiziltas S, Masatlioglu S, Oguz F, Ergin H (2008) Mycophenolate mofetil versus azathioprine in the maintenance therapy of lupus nephritis. Ren Fail 30(9):865-869

Steinberg AD, Steinberg SC (2005) Long-term preservation of renal function in patients with lupus nephritis receiving treatment that includes cyclophosphamide versus those treated with prednisone only. Arthritis Rheum 34(8):945-950

Tan EM, Cohen AS, Fries JF, Masi AT, Mcshane DJ, Rothfield NF, Schaller JG, Talal N, Winchester RJ (1982) The 1982 revised criteria for the classification of systemic lupus erythematosus. Arthritis Rheum 25(11):1271-1277

Tse K, Tang CSO, Lio W, Lam M, Chan T (2006) Quality of life comparison between corticosteroidand-mycofenolate mofetil and corticosteroidand-oral cyclophosphamide in the treatment of severe lupus nephritis. Lupus 15(6):371-379

Walsh M, James M, Jayne D, Tonelli M, Manns BJ, Hemmelgarn BR (2007) Mycophenolate mofetil for induction therapy of lupus nephritis: a systematic review and meta-analysis. Clin J Am Soc Nephrol 2(5):968-975

Weening JJ, D'agati V, Schwartz MM, Seshan SV, Alpers CE, Appel GB, Balow JE, Bruijn JA, Cook T, Ferrario F, Fogo AB, Ginzler EM, Hebert L, Hill G, Hill P, Jennette JC, Kong NC, Lesavre P, Lockshin M, Looi LM, Makino H, Moura LA, Nagata M (2004) The classification of glomerulonephritis in systemic lupus erythematosus revisited. Kidney Int 65(2):521-530
Weng MY, Weng CT, Liu MF (2010) The efficacy of low-dose mycophenolate mofetil for treatment of lupus nephritis in Taiwanese patients with systemic lupus erythematosus. Clin Rheumatol 29(7):771-775

Zhu B, Chen N, Lin Y, Ren H, Zhang W, Wang WM, Pan X, Yu H (2007) Mycophenolate mofetil in induction and maintenance therapy of severe lupus nephritis: a meta-analysis of randomized controlled trials. Nephrol Dial Transplant 22(7):1933-1942

doi:10.1186/2193-1801-3-638

Cite this article as: Rezaieyazdi et al: Efficacy of long-term maintenance therapy with mycophenolate mofetil in lupus nephritis. SpringerPlus 2014 3:638

\section{Submit your manuscript to a SpringerOpen ${ }^{\odot}$ journal and benefit from:}

- Convenient online submission

- Rigorous peer review

- Immediate publication on acceptance

- Open access: articles freely available online

- High visibility within the field

- Retaining the copyright to your article

Submit your next manuscript at $>$ springeropen.com 